\title{
Exhaled nitric oxide is not elevated in the inflammatory airways diseases of cystic fibrosis and bronchiectasis
}

\author{
L.P. Ho, J.A. Innes, A.P. Greening
}

Exhaled nitric oxide is not elevated in the inflammatory airways diseases of cystic fibrosis and bronchiectasis. L.P. Ho, J.A. Innes, A.P. Greening. (OERS Journals Ltd 1998.

ABSTRACT: Airways inflammation has been associated with increased nitric oxide (NO) in the exhaled breath. It was, therefore, questioned whether exhaled NO could act as an indicator of the severity of airways inflammation in the chronic suppurative lung diseases cystic fibrosis $(\mathrm{CF})$ and bronchiectasis.

NO levels in a single exhalation were measured using a chemiluminescence analyser. Thirty-six patients with $\mathrm{CF}$ and 16 with bronchiectasis were studied and compared with 22 normal subjects and 35 asthmatic patients. All subjects were nonsmokers and all measurements were made when patients were clinically stable. In addition, exhaled NO was measured in $10 \mathrm{CF}$ patients at the time of onset of an acute infective exacerbation and followed for 7 days during the treatment of the exacerbation in eight of the 10 patients.

No significant differences were found in NO levels in patients with CF or bronchiectasis compared with normals (median 4.0, 5.5 and 4.4 parts per billion (ppb), respectively), but all were lower than in asthma patients $(10.4 \mathrm{ppb})$. The NO levels in the $\mathrm{CF}$ patients at time of exacerbation were not increased and did not change during treatment.

These data show that nitric oxide levels in the exhaled breath of patients with chronic suppurative lung diseases, in contrast to asthma, are not elevated, despite the presence of substantial airways inflammation. Possible explanations include poor diffusion of nitric oxide across increased and viscous airway secretions, removal of nitric oxide by reaction with reactive oxygen species in the inflamed environment and failure of upregulation of epithelial inducible nitric oxide synthase in chronic suppurative conditions.

Eur Respir J 1998; 12: 1290-1294.
Respiratory Unit and Scottish Adult Cystic Fibrosis Service, Western General Hospital NHS Trust, Edinburgh, UK.

Correspondence: A.P. Greening

Respiratory Unit

Western General Hospital NHS Trust

Crewe Road South

Edinburgh EH4 2XU

UK

Fax: 441313433989

Keywords: Asthma

bronchiectasis

cystic fibrosis

exhaled breath

inducible nitric oxide synthase nitric oxide

Received: October 301997

Accepted after revision June 251998

L.P. Ho was supported by MRC programme grant no. G9313618. The NO analyser was purchased through a grant from Glaxo Wellcome Research and Development Ltd.
Nitric oxide (NO) is an important mediator of biological functions in the airways [1], regulating airway smooth muscle contractility, mucus secretion from airways mucus glands and vasodilatation and mediating inflammatory responses [2]. Central to the formation of $\mathrm{NO}$ and its reactive nitrogen products is the enzyme nitric oxide synthase (NOS) which has been characterized in almost all cells within the airways [3]. Expression of one of the isoform of NOS (inducible NOS (iNOS)) has been shown to be increased in the airway epithelium of asthmatics [4] and NO in the exhaled air of these patients has also been seen to be elevated [5, 6]. Activated neutrophils, eosinophils and macrophages produce large amounts of NO [7-9] and iNOS is known to be upregulated by pro-inflammatory cytokines [4]. This has generated a considerable amount of interest in the role of $\mathrm{NO}$ in the pathophysiology of inflammatory airways diseases. There is evidence to suggest that NO acts to amplify asthmatic inflammation by promoting the secretion of interleukin-5 (IL-5), increasing mucosal hyperaemia, and by direct cellular damage [10-12]. In addition, increased levels of exhaled NO have been reported in patients with bronchiectasis and upper respiratory tract infection $[13,14]$. Thus, NO levels in the exhaled air have

For editorial comments see page 1248. been put forward as a reflection of the severity of airways inflammation, primarily by virtue of it being a byproduct of inflamed epithelium and inflammatory cell influx to the airways. In cystic fibrosis (CF) or bronchiectasis, where chronic suppuration and bacterial colonization dominate, such a marker could be a useful guide to patients' responses to treatment.

The levels of exhaled NO in the chronic inflammatory airways diseases, $\mathrm{CF}$ and bronchiectasis were studied using a validated method of measurement which excludes upper airway air contamination and compared with those of normal subjects and asthmatics, a group known to show high exhaled NO levels. In addition, the effect of infective exacerbation on exhaled $\mathrm{NO}$ in patients with $\mathrm{CF}$ was examined.

\section{Subjects and methods}

\section{Subjects and patients}

Thirty-six patients with $\mathrm{CF}$ were recruited from the Scottish Adult Cystic Fibrosis Service. All except three had fully defined genotypes. Disease severity varied widely, with predicted forced expiratory volume in one second 
(FEV1) ranging 18-100\%. Patients with concomitant asthma and those who were on inhaled steroids were excluded.

Sixteen patients with bronchiectasis were recruited from the authors' respiratory outpatient clinic. Bronchiectasis was diagnosed by classical chest radiographic changes in four patients, by computed tomography (CT) in six patients and by bronchography in six patients. In five patients, bronchiectasis was secondary to childhood bronchopneumonia, three cases were due to tuberculosis, one to whooping cough, two to measles and five had no determined cause. Six patients were on inhaled steroids. None had evidence of asthma or allergic bronchopulmonary aspergillosis. This group, too, had widely varying disease severity (FEV1 $32-91 \%$ predicted). As a positive control, 34 patients with asthma were recruited from the respiratory outpatient clinic and from general practices. All patients had documented reversible air flow obstruction and were on inhaled $\beta_{2}$-agonists. Twenty-three were on inhaled steroids (doses ranging 400-3,200 $\mu \mathrm{g} \cdot \mathrm{day}^{-1}$ ). Eleven asthmatics were steroid naive. Both patients treated and those not treated with inhaled steroids were included to provide a comparison for similar therapeutic differences in the bronchiectasis group. The FEV1 for the whole group ranged $34-100 \%$ pred. All patients were nonsmokers and clinically stable. Twenty-two healthy volunteers were recruited from the hospital staff. These were nonsmokers, had no respiratory tract symptoms, and did not have active allergic rhinitis at the time of sampling. The mean ages $( \pm \mathrm{SD})$ were $32.0 \pm 12.6,27.1 \pm 8.6,52.5 \pm 14.7$ and $45.2 \pm 16.8$ yrs for normal subjects, CF, bronchiectasis and asthma patients, respectively.

In $10 \mathrm{CF}$ patients (eight males, mean age $26.5 \mathrm{yrs}$ ), exhaled NO was also examined during infective pulmonary exacerbations. Levels were measured within $24 \mathrm{~h}$ of onset of an infective exacerbation, defined as a worsening of clinical condition requiring i.v. antibiotics accompanied by a fall of $400 \mathrm{~mL}$ or $20 \%$ of usual FEV1. All measurements were performed before or within $6 \mathrm{~h}$ of commencement of i.v. antibiotics. In eight of these subjects, serial exhaled NO measurements and lung function were recorded over 7 days.

The relationships were examined between exhaled NO and lung function, as measured by FEV1, and in the normal volunteers, between exhaled NO and age.

Informed consent was obtained from all subjects and the study was approved by the Lothian Health Ethics Committee.

\section{Measurement of exhaled nitric oxide}

NO was measured in the exhaled breath using a sensitive chemiluminescence analyser (LR 2000; Logan Research, Kent, UK) with a detection limit of $0.1 \mathrm{ppb}$ of NO. The analyser was calibrated daily with $\mathrm{NO} / \mathrm{N}_{2}$ calibration gas containing $103 \mathrm{ppb}$ NO (BOC, Guildford, UK). The subject inspired to total lung capacity and, with no breath hold, exhaled into a sampling tube (containing a flow resistor) at a constant rate of $250 \mathrm{~mL} \cdot \mathrm{s}^{-1}$. This maintained a constant mouth pressure of $5 \mathrm{cmH}_{2} \mathrm{O}$ during the exhalation, effected by the subject observing a visual display of this pressure. Air was drawn from the sampling tube at a standard rate of $4 \mathrm{~mL} \cdot \mathrm{s}^{-1}$. This method has been shown to

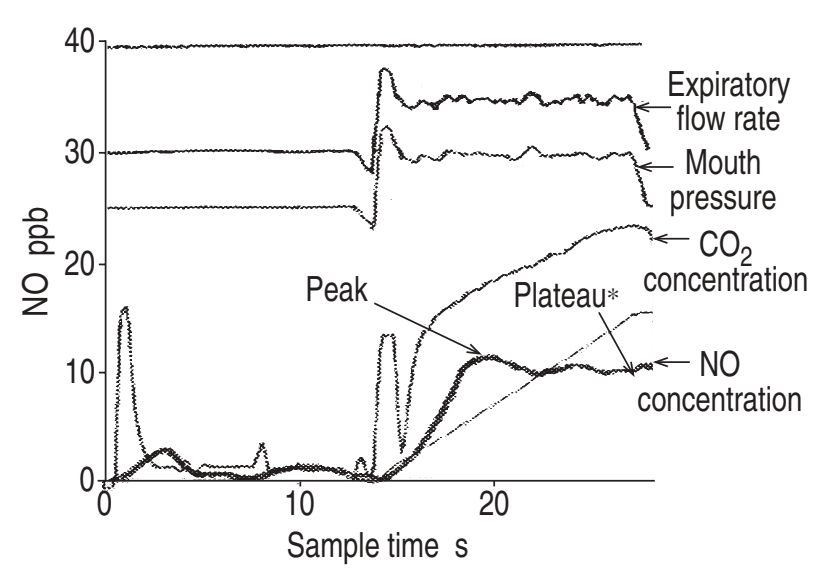

Fig. 1. - Computer screen display of exhaled nitric oxide (NO) measurement. Mouth pressure, exhalation flow rate, carbon dioxide and NO concentration in the exhaled breath are measured simultaneously as shown. The representative plateau level for any particular exhalation is the point at the end of the plateau phase corresponding to constant mouth pressure $(*)$. The ordinate, showing values for NO in the figure above, can be changed to show values for $\mathrm{CO}_{2}(\mathrm{kPa})$, mouth pressure $\left(\mathrm{cmH}_{2} \mathrm{O}\right)$ and exhalation flow rate $\left(\mathrm{mL} \cdot \mathrm{s}^{-1}\right)$. ppb: parts per billion.

exclude contamination of the lower respiratory tract with nasal air, probably by elevation of the soft palate against the oropharynx, thus sealing off the posterior nasopharynx [15]. Representative values were taken from the plateau at the end of the exhalation profile and the mean of triplicate measurements was recorded (fig. 1).

The reproducibility of NO plateau levels was addressed by making measurements on seven subjects from three to six occasions separated by at least 1 day. Since the ambient NO level in Edinburgh ranged $0.4-50 \mathrm{ppb}$, the potential effects of ambient NO levels were also examined by determining the influence of additional NO in the inspired breath in three subjects. Plateau exhaled NO levels for these subjects were compared after they inhaled NO at 0.4 $\mathrm{ppb}$ (the ambient NO level on the day of measurement) and $80 \mathrm{ppb}$.

\section{Statistical analyses}

To test the reproducibility of plateau NO measurements, Bartlett's test for equality of variance within each patient was applied and analysis of variance (ANOVA) was then used to determine variance and, thus, global standard deviation. For comparison of NO levels between groups, the Mann-Whitney rank sum test was used since the asthmatic groups showed deviation from normal Gaussian distribution. The correlation between lung function and age with exhaled NO was measured using Pearson's product moment correlation test. For all tests, $\mathrm{p}<0.05$ was assumed to achieve statistical significance.

\section{Results}

\section{Reproducibility of nitric oxide measurement}

Equality of variance within each patient tested by Bartlett's test showed no significant difference between patients. ANOVA for seven subjects with repeated measurements 
Table 1. - Effect of inhaling 80 parts per billion (ppb) nitric oxide (NO) compared with ambient air (0.4 ppb NO) on the peak and plateau values of NO in the exhaled breath

\begin{tabular}{|c|c|c|c|c|c|c|}
\hline \multirow[b]{2}{*}{ Inhaled NO } & \multicolumn{2}{|c|}{ Subject 1} & \multicolumn{2}{|c|}{ Subject 2} & \multicolumn{2}{|c|}{ Subject 3} \\
\hline & Peak NO & Plateau NO & Peak NO & Plateau NO & Peak NO & Plateau NO \\
\hline Atmospheric air (0.4 ppb NO) & 7.9 & 7.8 & 8.6 & 7.6 & 3.9 & 3.5 \\
\hline $80 \mathrm{ppb}$ after a single inhalation & 39.0 & 7.7 & 36.1 & 5.8 & 25.8 & 3.1 \\
\hline & 44.2 & 7.7 & 48.0 & 6.3 & 26.9 & 2.7 \\
\hline & 40.1 & 7.4 & 45.3 & 6.8 & 23.6 & 2.4 \\
\hline $80 \mathrm{ppb}$ after three tidal breaths & & 7.8 & & & & \\
\hline $80 \mathrm{ppb}$ after five tidal breaths & & 7.3 & & & & \\
\hline $80 \mathrm{ppb}$ after $5 \mathrm{~min}$ of tidal breathing & & 7.3 & & & & \\
\hline
\end{tabular}

Peak, but not plateau, values were affected by inhaled NO.

(between three and six times) of exhaled NO gave a pooled standard deviation of $0.84 \mathrm{ppb}$ and coefficient of variation equal to 0.24 . The $95 \%$ confidence interval for any measurement of NO is, thus, $\pm 1.72 \mathrm{ppb}$.

\section{Effect of ambient nitric oxide on measurement}

During exhalation, the plateau NO level, in contrast to the peak NO level, did not differ whether subjects inhaled $0.4 \mathrm{ppb}$ or $80 \mathrm{ppb}$ NO (table 1).

\section{Effect of age on nitric oxide levels}

No correlation was found between age and exhaled NO $(\mathrm{r}=0.28, \mathrm{p}=0.2$ in healthy volunteers $)$.

Exhaled nitric oxide in cystic fibrosis, bronchiectasis, asthma and normal subjects

NO levels in patients with $\mathrm{CF}$, bronchiectasis and normal subjects did not differ significantly from each other. The median value in patients with $\mathrm{CF}$ was $4.0 \mathrm{ppb}$ (inter-

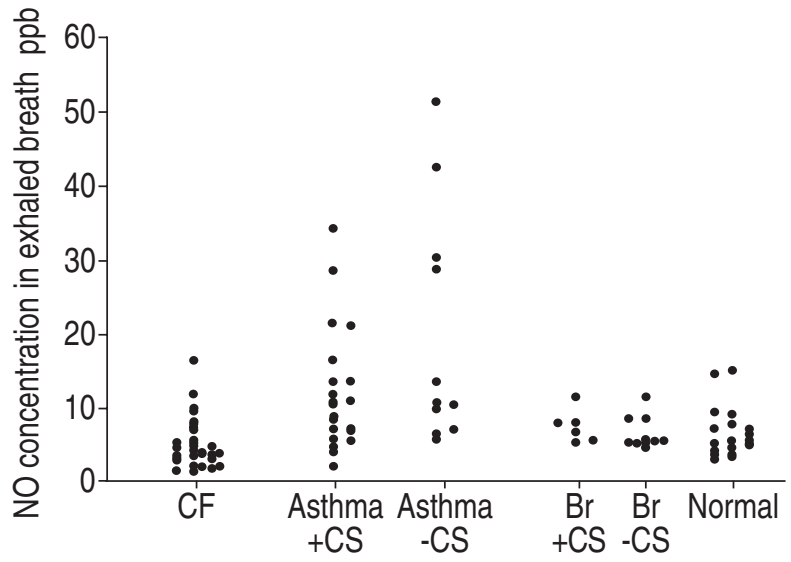

Fig. 2. - Distribution of nitric oxide (NO) concentration in exhaled breath in normal subjects and patients with cystic fibrosis (CF), asthma and bronchiectasis (Br). Patients taking inhaled steroids are shown as $+\mathrm{CS}$ and those not are shown as -CS. The median (interquartile range) NO level for each group is CF: 4.0 (2.8-7.2); asthma (+CS): $10.1(5.8-$ 13.3); asthma -CS: 10.4 (7.3-29.4); bronchiectasis +CS: 6.7 (4.9-7.3); bronchiectasis -CS: 4.7 (4.4-7.8); and normal subjects: 4.4 (1.0-7.8). Only the asthmatic groups (irrespective of steroid treatment) had significantly higher NO levels than normal subjects $(\mathrm{p}<0.05)$. ppb: parts per billion. quartile range 3.1 ); in bronchiectasis the median value was $5.5 \mathrm{ppb}$ (interquartile range 3.1 ); and normal subjects had a median value of $4.4 \mathrm{ppb}$ (interquartile range 3.4). Patients with asthma had a significantly higher median value compared to all the other groups $(10.4$, interquartile 16.9). There was a positively skewed distribution and a large range of values in the asthmatic population (fig. 2).

\section{Correlation between lung function and exhaled nitric} oxide in stable patients

There was a weak but statistically significant positive correlation between exhaled $\mathrm{NO}$ and FEV1 in patients with $\mathrm{CF}(\mathrm{r}=0.48, \mathrm{p}<0.05)$ (fig. 3 ). Thus, patients with better lung function appeared to have higher exhaled NO levels. This was not seen in bronchiectasis or asthma.

Infective pulmonary exacerbations and exhaled nitric oxide in patients with cystic fibrosis

During pulmonary exacerbations exhaled NO remained within the normal range (fig. 4). In seven out of 10 patients, the values were the same or lower than when clinically stable. In three patients there was a small but nonsignificant rise. For eight patients serial exhaled NO measurements made over seven days after commencement of i.v. antibiotics showed no consistent trend with time (fig. 5).

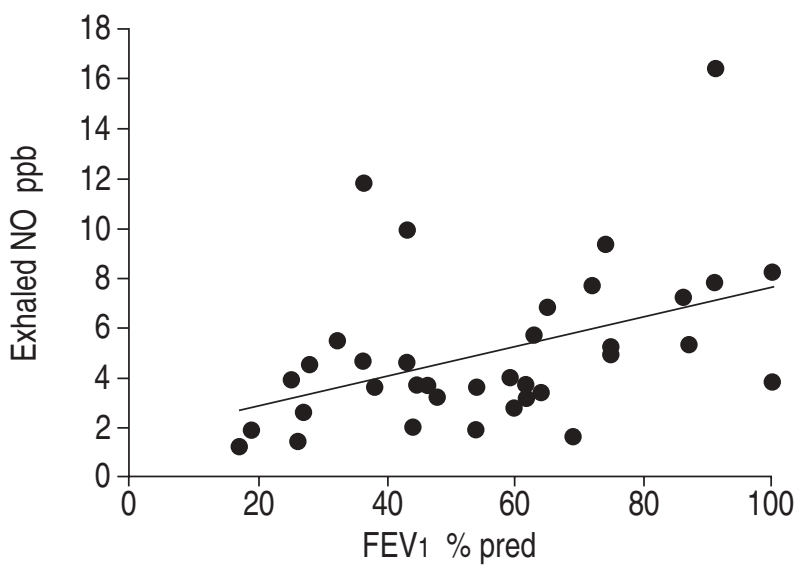

Fig. 3. - Relationship between exhaled nitric oxide (NO) and lung function in patients with cystic fibrosis $(r=0.48, \mathrm{p}<0.05)$. FEV1: forced expiratory volume in one second; ppb: parts per billion. 


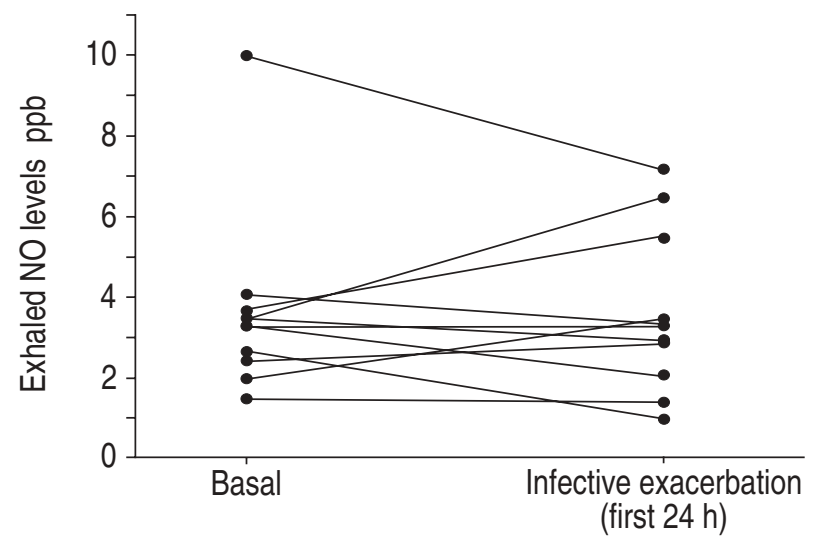

Fig. 4. - Levels of exhaled nitric oxide (NO) in patients with cystic fibrosis while clinically stable (basal) compared with levels during the first $24 \mathrm{~h}$ of pulmonary exacerbation. ppb: parts per billion.

\section{Discussion}

The discovery that exhaled NO is raised in asthmatics has led to the expectation that it may provide a tool for measurement of inflammation in the lower respiratory tract. However, two general factors have prevented full validation of this as a reliable measure. Firstly, the exhaled NO has been measured using different techniques producing widely differing values. The main contributions to these differences appear to be contamination from nasal air, the use of different exhalation rates and the use of single exhalation as opposed to collection in a bag. Secondly, our understanding of the cellular source, anatomical origins and factors modulating the release of NO into the exhaled air is incomplete. The conclusion that exhaled NO may be a general marker of airways inflammation on the basis of its elevation in asthmatics may, therefore, be premature.

In this study, a method was used which excluded nasal air and employed one exhalation flow rate for all patients and the reproducibility of the methods was demonstrated. Since the difference in mean age between the CF and bronchiectasis group was large ( 27.1 versus $57.2 \mathrm{yrs}$ ), the relationship of exhaled NO with age was also tested but no significant correlation was found.

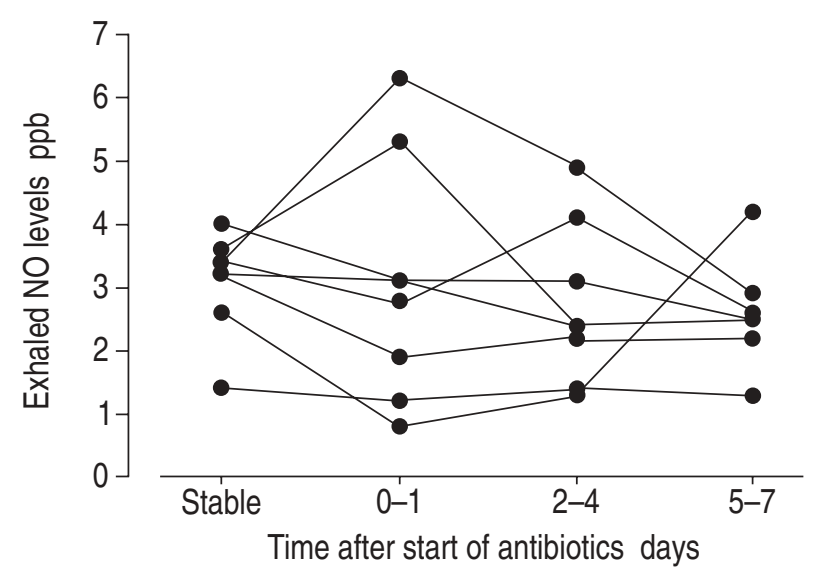

Fig. 5. - Changes in exhaled nitric oxide (NO) for individual patients over 7 days after commencement of i.v. antibiotics. ppb: parts per billion.
Exhaled NO levels in CF and bronchiectasis were no different from those in normal subjects. However, in keeping with published work, high levels in asthmatics were detected. The findings in CF support and extend recent reports, all in children [16-18]. Methodological differences may not allow absolute comparison but all papers reported NO values in CF patients that were no different from control subjects. In none of these studies was nasal NO definitely excluded. In one study the response time of the analyser was slow, risking contamination from the ambient air and, indeed, the authors showed that with their method, there was a good correlation between exhaled NO and ambient NO [18]. Furthermore, levels were obtained from a collection bag containing mixed expired air. In the third study, patient numbers were small [16]. Importantly, the present study demonstrated, for the first time, that in $\mathrm{CF}$ patients with infective exacerbation levels did not change either during the first $24 \mathrm{~h}$ of infection or with follow-up over time. This meant, in addition to low levels during a stable clinical state, an increase in inflammation associated with active exacerbation did not result in increased NO levels.

The findings in bronchiectasis were unexpected and in contrast to the only other published report [14]. The different methodology used in measuring exhaled NO may explain the different results in the bronchiectasis patients. KHARITONov et al. [14] used the peak level from a long and slow exhalation as the representative NO value. The peak level can be very variable and sensitive to even a short period of breath holding [18-20] and, as shown in the present study, be influenced by ambient NO levels (table 1). Further, the much lower, uncontrolled and variable exhalation rate probably makes a major contribution to the differences in levels within the group, since exhalation rate has been shown to correlate negatively with NO levels in exhaled breath [21].

The absence of elevated levels of NO in the exhaled breath of patients with $\mathrm{CF}$ and bronchiectasis has a number of potential explanations. There may be a decrease in diffusion of NO across secretions of increased viscosity and volume. This may promote the reaction of NO with other reactive species or simply with water, with the formation of nitrite and nitrate. Diffusion limitation into the lumen may also encourage an increase in NO uptake in the bronchial or pulmonary circulation. This is also supported by the finding that the levels were uniformly low in both $\mathrm{CF}$ and bronchiectasis patients, in the former group irrespective of increase in inflammation and in the latter irrespective of steroid treatment. In other words, the secretion layer appeared to be the final barrier to the detection of produced NO. Alternatively, in a suppurative and inflamed environment, the presence of reactive oxygen species in the vicinity of the NO production may result in chemical interaction, with the effective removal of NO by formation of peroxynitrite, for example. Indeed, NO has been shown to be a potent scavenger of reactive oxidants in the lung [22].

Either explanation would be consistent with the finding that NO levels in the breath of CF patients correlated positively with lung function. Patients with mild disease would have less viscid and fewer secretions and less production of reactive oxygen species. A third possibility is that the high levels of NO in asthma reflect, in that condition, the importance of upregulation of iNOS, particularly 
in the airway epithelium. If in CF iNOS fails to be upregulated, then the exhaled NO levels would be no different from normal. One study has suggested that this may be the case, with an absence of iNOS expression in CF bronchial explants [23]. If failure of iNOS upregulation is a cause for the low levels of exhaled NO in these patients, it remains unclear whether this is secondary to the effect of chronic inflammation or whether there is an inherent lack of gene expression related to the CF transmembrane receptor mutation. The former would seem likely in view of the decrease in both CF and bronchiectasis and also with the demonstration of normal iNOS expression in inflammatory cells from $\mathrm{CF}$ bronchial explants [23].

Whatever the cause, low NO generation in $\mathrm{CF}$ and bronchiectasis may have important implications for host defence, since NO has marked in vitro antimicrobial properties and a decrease in production by the epithelium may result in reduced local bacterial killing, thus facilitating chronic bacterial colonization and repeated infections.

The finding with inhaled NO was interesting (table 1). Although the main aim was to prove that ambient NO did not affect expired lower respiratory tract NO, the results also suggest that gaseous NO appears highly labile. Within the duration of a single inhalation and exhalation (approximately 10-15 s) it has either diffused into the pulmonary circulation or metabolized to other products. Thus, what is detected at the end of an expired breath probably represents very high and continuously produced NO and exhaled NO may not detect lower (but still elevated) levels of NO generation. The results also showed that the peak, as opposed to plateau, level in a single exhalation profile is affected by the inspired level. This is probably an effect of the immediate expiration of inhaled NO from the anatomical dead space.

In summary, these results have shown that, using a method which excluded nasal air contamination and applied a standard exhalation rate in all patient groups, exhaled nitric oxide is not elevated in the inflammatory airways diseases of cystic fibrosis and bronchiectasis, in contrast to asthma. This suggests that exhaled nitric oxide may not be a helpful marker of airways inflammation in inflammatory diseases other than asthma. It is unclear whether these data reflect a lack of nitric oxide production in the patients or an inability to detect the nitric oxide production. If it proves to be the former, additional studies in cystic fibrosis and bronchiectasis will be important to clarify the role and contribution of nitric oxide in prevention of bacterial colonization and infection.

Acknowledgements: The authors would like to thank I. Grant and J. Kelly for their help with the production of high levels of NO in examining the effect of ambient NO on exhaled NO and A. Carothers, statistician, for help with statistical analysis of the results.

\section{References}

1. Nathan C, Xie QW. Regulation and biosynthesis of NO. $J$ Biol Chem 1994; 269: 13725-13728.

2. Moncada S. NO: mediator, modulator, and pathophysiologic entity. J Lab Clin Med 1992; 120: 187-191.

3. Gaston B, Drazen JM, Loscalzo J, Stamler JS. The biology of NO in the airways. Am J Respir Crit Care Med 1994; 149: $538-551$.
4. Robbins RA, Barnes PJ, Springall DR, et al. Expression of iNOS in human lung epithelial cells. Biochem Biophys Res Commun 1994; 203: 209-218.

5. Kharitonov SA, Yates D, Springall DR, et al. Increased NO in exhaled air of asthmatic patients. Lancet 1994; 343: 133-136.

6. Alving K, Witzberg E, Lundberg M. Increased amount of NO in exhaled air of asthmatics. Eur Respir J 1993; 6: 1368-1370.

7. Jorens PG, van Overveld FJ, Bult H, Vermeire PA, Herman AG. L arginine dependent production of NO by pulmonary macrophages. Eur J Pharmacol 1991; 200: 205-209.

8. del Pozo V, de Arruda-Chaves E, de Andres B, et al. Eosinophils transcribe and translate mRNA for iNOS. $J$ Immunol 1997; 158: 859-864.

9. Evans TJ, Buttery LDK, Carpenter A, Springall DR, Polak JM, Cohen J. Cytokine treated human neutrophils contain iNOS that produces nitration of ingested bacteria. Proc Natl Acad Sci USA 1996; 93: 9553-9558.

10. Barnes PJ, Liew FY. NO and asthmatic inflammation. Immunol Today 1995; 16: 128-130.

11. Beckman JS, Beckman TW, Chen J, Marshall PA, Freeman BA. Apparent hydroxyl radical production by peroxynitrite: implications for endothelial injury from NO and superoxide. Proc Natl Acad Sci USA 1990; 87: 16201624.

12. Kuo H-P, Liu S, Barnes PJ. The effect of endogenous NO on neurogenic plasma exudation in guinea-pig airways. Eur J Pharmacol 1992; 221: 385-388.

13. Kharitonov SA, Yates D, Barnes PJ. Increased NO in exhaled air of normal human subjects with upper respiratory tract infections. Eur Respir J 1995; 8: 295-297.

14. Kharitonov SA, Athol UW, O'Connor BJ, et al. Elevated levels of NO in bronchiectasis. Am J Respir Crit Care Med 1995; 151: 1889-1893.

15. Kharitonov S, Barnes PJ. There is no nasal contribution to exhaled NO during exhalation against resistance or during breath holding. Thorax 1997; 52: 540-544.

16. Lundberg JON, Nordvall SL, Weitzberg E, Kollberg H, Alving K. Exhaled nitric oxide in paediatric asthma and cystic fibrosis. Arch Dis Child 1996; 75: 323-326.

17. Balfour-Lynn IM, Lavarty A, Dinwiddie R. Reduced upper airway nitric oxide in cystic fibrosis. Arch Dis Child 1996; 75: 319-322.

18. Dötsch J, Demirakça S, Terbrack HG, Hüls G, Rascher W, Kühl PG. Airway nitric oxide in asthmatic children and patients with cystic fibrosis. Eur Respir J 1996; 9: 2537-2540.

19. Persson M, Zetterstrom O, Agrenius V, Ihre E, Gustaffson L. Single breath NO measurements in asthmatic patient and smokers. Lancet 1994; 343: 146-147.

20. Lundberg JON, Witzberg E, Nordvall SL, Kuylenstierna R, Lundberg JM, Alving K. Primarily nasal origin of exhaled NO and absence in Kartegener's syndrome. Eur Respir J 1994; 7: 1501-1504.

21. Silkoff P, MacLean P, Slutsky A, et al. Marked flow dependence of exhaled NO using a new technique to exclude nasal NO. Am J Respir Crit Care Med 1997; 155: 260-267.

22. Wink D, Hanbeur I, Krishna M, Degraff W, Gamson J, Mitchell J. NO protects against cellular damage and cytotoxicity from ROS. Proc Natl Acad Sci USA 1993; 90: 9813-9817.

23. Meng Q-H, Springall DR, Bishop AE, et al. Lack of inducible nitric oxide synthase in bronchial epithelium: a possible mechanism of susceptibility to infection in CF. $J$ Pathol 1998; 184: 323-331. 